\title{
The pulmonary circulation of homozygous or heterozygous eNOS-null mice is hyperresponsive to mild hypoxia
}

\author{
Karen A. Fagan, ${ }^{1,2}$ Brian W. Fouty, ${ }^{1,2}$ Robert C. Tyler, ${ }^{1}$ Kenneth G. Morris, Jr., ${ }^{1}$ \\ Lisa K. Hepler, ${ }^{1}$ Koichi Sato, ${ }^{1}$ Timothy D. LeCras, ${ }^{1,5}$ Steven H. Abman, ${ }^{1,5}$ \\ Howard D. Weinberger, ${ }^{3}$ Paul L. Huang, ${ }^{6}$ Ivan F. McMurtry, ${ }^{1,2}$ and David M. Rodman ${ }^{1,2,4}$ \\ ${ }^{1}$ Cardiovascular Pulmonary Research Laboratory, \\ ${ }^{2}$ Division of Pulmonary Sciences and Critical Care Medicine, \\ ${ }^{3}$ Division of Cardiology, \\ ${ }^{4}$ Department of Physiology, and \\ ${ }^{5}$ Department of Pediatrics, University of Colorado Health Sciences Center, Denver, Colorado 80262, USA \\ ${ }^{6}$ Massachusetts General Hospital, Boston, Massachusetts 02114, USA \\ Address correspondence to: K.A. Fagan, Cardiovascular Pulmonary Research Laboratory, University of Colorado Health Sciences \\ Center, 4200 East Ninth Avenue, C-272, Denver, Colorado 80262, USA. Phone: (303) 315-8628; Fax: (303) 315-4871; \\ E-mail: karen.fagan@uchsc.edu \\ Received for publication April 28, 1998, and accepted in revised form December 1, 1998.
}

\begin{abstract}
Acute hypoxic vasoconstriction and development of hypoxic pulmonary hypertension (PHTN) are unique properties of the pulmonary circulation. The pulmonary endothelium produces vasoactive factors, including nitric oxide (NO), that modify these phenomena. We tested the hypothesis that NO produced by endothelial nitric oxide synthase (eNOS) modulates pulmonary vascular responses to hypoxia using mice with targeted disruption of the eNOS gene $\left(\mathrm{eNOS}^{-/-}\right)$. Marked PHTN was found in $\mathrm{eNOS}^{-/-}$mice raised in mild hypoxia when compared with either controls or $\mathrm{eNOS}^{-/-}$mice raised in conditions simulating sea level. We found an approximate twofold increase in partially and fully muscularized distal pulmonary arteries in $\mathrm{eNOS}^{-/-}$mice compared with controls. Consistent with vasoconstriction being the primary mechanism of PHTN, however, acute inhalation of $25 \mathrm{ppm} \mathrm{NO}$ resulted in normalization of RV pressure in $\mathrm{eNOS}^{-/-}$mice. In addition to studies of eNOS ${ }^{-/-}$mice, the dose-effect of eNOS was tested using heterozygous $\mathrm{eNOS}^{+/-}$mice. Although the lungs of $\mathrm{eNOS}^{+/-}$mice had $50 \%$ of normal eNOS protein, the response to hypoxia was indistinguishable from that of eNOS $-/$ mice. We conclude that eNOSderived $\mathrm{NO}$ is an important modulator of the pulmonary vascular response to chronic hypoxia and that more than $50 \%$ of eNOS expression is required to maintain normal pulmonary vascular tone.
\end{abstract}

J. Clin. Invest. 103:291-299 (1999).

\section{Introduction}

Acute hypoxic pulmonary vasoconstriction (HPV) and the development of chronic hypoxic pulmonary hypertension (PHTN) are cardinal features of the pulmonary circulation that differentiate this vascular bed from the systemic circulation. Nitric oxide (NO) produced by pulmonary vascular endothelium is thought to modulate pulmonary vascular responses to a variety of vasoconstrictor stimuli, including hypoxia (1-8). However, despite intensive investigation over the past decade, the role of endotheliumderived nitric oxide (EDNO) in modulating tone and structural remodeling of the chronically hypoxic pulmonary circulation remains controversial (9-13).

Simultaneous pharmacologic inhibition of all three isoforms of nitric oxide synthase (NOS) results in acutely increased pulmonary vascular resistance and augmented HPV (1, 14-15). However, chronic NOS inhibition does not result in PHTN and does not augment the development of hypoxic PHTN (16). These results present a paradox: If EDNO modulates acute HPV, why is pharmacologic inhibition of NOS not associated with either normoxic PHTN or accentuated chronic hypoxic
PHTN? One possibility is that HPV is redundantly modulated, and the loss of endothelial nitric oxide synthase (eNOS)-derived NO alone is not sufficient to produce PHTN. Alternatively, the experimental approaches taken in the past to test this question may have been inadequate because of nonspecific effects of pharmacologic inhibitors of NOS, difficulty maintaining NOS inhibition, or confounding effects of simultaneous inhibition of all three isoforms of NOS.

Mice with targeted disruption of eNOS (eNOS ${ }^{-/-}$mice) have recently been constructed and the vascular phenotype explored $(17,18)$. Systemic hypertension and augmented structural remodeling after vascular injury have been reported $(19,20)$. Steudel et al. (21) investigated the pulmonary vascular phenotype of $\mathrm{eNOS}^{-/-}$mice, finding increased pulmonary vascular resistance, but only minimal PHTN, and no evidence of pulmonary vascular remodeling. More recently, this group also found enhanced chronic hypoxic PHTN in eNOS-null mice (22). These studies were limited, however, to mice exposed to severe hypoxia $\left(\mathrm{FiO}_{2}=11 \%\right)$ and studied under general anesthesia with hyperoxic $\left(\mathrm{FiO}_{2}=80 \%\right)$ mechanical ven- 
tilation. Thus, while the studies support a role for eNOS in modulating the chronic pulmonary vascular response to severe hypoxia, the relevance of these observations to clinically relevant levels of hypoxia was not addressed.

This study was designed to address the following unresolved issues: (a) Does eNOS-derived NO modulate the pulmonary vascular response to mild hypoxia in vivo; $(b)$ Is there a dose-response to the loss of eNOS (i.e., do mice with heterozygous disruption of eNOS have a pulmonary vascular phenotype); and (c) What are the relative contributions of vasoconstriction and vascular remodeling to hypoxic PHTN seen in eNOS ${ }^{-/-}$and +/mice. These three questions were studied by measuring in vivo hemodynamics as well as right ventricular (RV) hypertrophy in $\mathrm{eNOS}^{-/-}, \mathrm{eNOS}^{+/-}$, and wild-type control mice exposed to either normoxia, mild hypoxia, or severe hypoxia for four weeks. To determine the relative contributions of vasoconstriction and structural remodeling, morphometry and acute vasodilator response to inhaled NO were performed. In addition, to test whether induction of alternative isoforms of NOS may have compensated for the loss of eNOS, semiquantitative PCR was used to measure steady-state mRNA levels of iNOS and $\mathrm{nNOS}$ in lungs from wild-type and $\mathrm{eNOS}^{-/-}$mice.

\section{Methods}

Unless otherwise specified, all chemicals and reagents were obtained from Sigma Chemical Co. (St. Louis, Missouri, USA).

Animals. Homozygous eNOS-deficient mice (-/-), generated as described previously (17), were used. Strain-specific C57BL6/SV129 controls were bred as the F1 generation of the cross of the parental wild-type strains, C57/6 (The Jackson Laboratory, Bar Harbor, Maine, USA) and SV129 (Taconic Farms, Germantown, New York, USA). Heterozygous $\mathrm{eNOS}^{+/-}$mice were bred as the F1 generation of matings between eNOS -1 mice and C57BL6/SV129 controls. A total of 141 animals was used in these studies. Animals were fed standard breeding rodent chow and water ad libitum. Genotype was confirmed by PCR of genomic DNA using standard techniques (23).

Blood gas and hematocrit analysis. Arterial samples $(0.5 \mathrm{ml})$ were obtained by percutaneous left ventricular (LV) sampling from lightly anesthetized mice spontaneously breathing room air (altitude $5280 \mathrm{ft}$ ), $25 \% \mathrm{O}_{2}$, or $11 \% \mathrm{O}_{2}$. In these experiments, mice were placed in the $\mathrm{FiO}_{2}$ that approximated that of chronic exposure. Samples were heparinized, with $0.4 \mathrm{ml}$ used for blood gas analysis and $0.1 \mathrm{ml}$ used for measurement of hematocrit. $\mathrm{PaO}_{2}, \mathrm{PCO}_{2}$, and $\mathrm{pH}$ were measured using a clinical blood gas analyzer (Radiometer, Copenhagen, Denmark). Hematocrit was measured using a capillary tube and standard techniques.

Hemodynamic studies. Male and female mice at ages $6-10$ weeks, approximately 17-30 g, were anesthetized with ketamine/xyalazine $(100 \mathrm{mg} / \mathrm{kg}$ and $15 \mathrm{mg} / \mathrm{kg}$, respectively) in a single hindquarter intramuscular injection. After an adequate level of sedation was achieved, mice were placed in a supine position while spontaneously breathing room air, and, after calibration of the zero point of the pressure transducer to the mid-anteroposterior (AP) diameter of the chest, a 26-gauge needle was introduced percutaneously into the thorax via a subxyphloid approach. Right and left ventricular pressures were measured using a pressure transducer (Gulton-Statham, Costa Mesa, California, USA) and recorded on a multichannel recorder (Grass Institute Co., Quinen, Massachusetts, USA). The heart rate under these conditions was between 300 and $500 \mathrm{bpm}$. If the heart rate fell below $300 \mathrm{bpm}$, it was assumed that the level of anesthesia or trauma was inhibiting cardiac function, and those measurements were excluded from analysis. Approximately 5\% of animals were excluded from analysis and were distributed evenly between all experimental groups. For inhaled NO experiments, the animal's head was placed in a hood that was flushed with a gas mixture with $21 \% \mathrm{O}_{2}$ plus $25 \mathrm{ppm} \mathrm{NO}$ (Scott Medical Products, Plumsteadville, Pennsylvania, USA). NO concentration was monitored by continuous electrochemical gas analysis (Pulmonox II; Pulmonox Medical Corp., Alberta, Canada). After hemodynamic measurement, animals were sacrificed and tissues were fixed for morphometric analysis.

Right ventricular bypertrophy. Immediately after sacrifice, the heart was resected, and the atria were removed to the plane of the atrial-ventricular valves. The RV free wall was then dissected free of the LV and septum. The RV and LV plus septum were weighed and the $\mathrm{RV} / \mathrm{LV}+\mathrm{S}$ ratio was calculated.

Oxygen environments. Mice were exposed to three levels of inspired $\mathrm{O}_{2}$ : normoxia, severe hypoxia, and an intermediate degree of hypoxia. As breeding and experiments were carried out in Denver, sea-level "normoxia" was simulated using a hyperbaric chamber $\left(\mathrm{Pb}=760 \mathrm{mmHg}\right.$, inspired $\left.\mathrm{PO}_{2}=150 \mathrm{mmHg}\right)$. Animals were housed in this chamber from birth to the time of study. Mice undergoing exposure to more severe hypoxia were housed in hypobaric chambers. Mice at age 6 weeks were placed into chambers for a period of 2-4 weeks with a simulated altitude of 17,000 $\mathrm{ft}\left(\mathrm{Pb}=410 \mathrm{mmHg}\right.$, inspired $\mathrm{PO}_{2}=76 \mathrm{mmHg}$ ). Exposure was continuous, with less than $1 \mathrm{~h} /$ day interruption for animal care and to remove animals for experimentation. An intermediate degree of hypoxia was produced by breeding mice in Denver (altitude $5,280 \mathrm{ft}, \mathrm{Pb}=630 \mathrm{mmHg}$, inspired $\mathrm{PO}_{2}=122 \mathrm{mmHg}$ ).

Western analysis. Protein from whole mouse lungs was extracted from homogenized tissues. Procedures for Western blotting were used as described previously (24), and quantification was performed after densitometry using Image 1.58 software (National Institutes of Health, Bethesda, Maryland, USA). A standard curve was created using known amounts of recombinant eNOS protein to ensure that experimental samples were loaded in the linear range of response of the photographic emulsion.

Semiquantitative reverse transcriptase-PCR. Total RNA from 100 mg of freshly obtained mouse lung was isolated using TriReagent (Molecular Research Center Inc., Cincinnati, Ohio, USA) protocols, and final product was suspended in $20 \mu \mathrm{ldepC} \mathrm{H}_{2} \mathrm{O}$. cDNA was synthesized from $2 \mu$ l of total RNA with SuperScript II reverse transcriptase (RT) protocols (GIBCO BRL, Rockville, Maryland, USA). cDNA was quantified on a spectrophotometer (GeneQuant; Pharmacia Biotech, Cambridge, United Kingdom). Primers sequences for murine iNOS and $\beta$-actin were obtained from CLONTECH (Palo Alto, California, USA), and RT-PCR protocols were followed. nNOS primers and protocols were obtained (25). PCR reactions were carried out on $1.5 \mu \mathrm{g}$ of cDNA. PCR products were electrophoresed in agarose and stained with ethidium bromide, and density of bands was determined using 1.58 Image software (National Institutes of Health) over a range of cycles, and a linear relationship between cycle number and product density was identified. After optimal cycle number was established for $\beta$-actin ( 32 cycles) and iNOS ( 32 cycles), $1.5 \mu \mathrm{g}$ of cDNA from experimental samples was studied, and relative density was expressed as iNOS density/ $\beta$-actin density.

Histologic analysis. Lungs from experimental animals were obtained after closed-chest pressure measurements. PBS was perfused through the pulmonary circulation to remove red blood cells. Lungs were then inflated with $1 \%$ agarose, fixed in methy carnoys (60\% methanol, $30 \%$ choloform, and $10 \%$ glacial acetic acid), embedded in paraffin, and sectioned. Sections were stained with polyclonal antimyosin primary antibody $(1: 1,000$; supplied by M. Frid, Colorado Health Sciences Center) and goat anti-rabbit secondary antibody conjugated to peroxidase. Substrate was developed with $\mathrm{DAB}$, and slides were counterstained with hematoxylin and studied with light microscopy at 40x. Airway anatomy was first identified at the level of the terminal 
bronchiole. Vessels corresponding to the level of the alveolar ducts $(<25 \mu \mathrm{m})$ were identified, and circumferential staining with myosin (dark brown) was determined as none, partial $(<75 \%)$, and full (>75\%). For each animal, at least 10 separate fields were studied and a minimum of 50 vessels per animal characterized. Additionally, at least 10 vessels per animal corresponding to the terminal bronchiole $(\sim 40 \mu \mathrm{m})$ were identified and images digitized (Nikon Instruments, Melville, New York, USA; and Optitronics Engineering, Goleta, California, USA), and medial thickness (area between intima and adventitia) and vessel diameter were measured using Image 1.61 software (National Institutes of Health). Neighboring vessels were counted and number of alveoli per vessel determined.

Statistical analysis. All results are represented as mean \pm SEM. Comparisons were made using one- or two-way ANOVA with Fisher post hoc test and unpaired $t$ tests, with $P<0.05$ accepted as significant. Morphometry data were analyzed using the Kruskal-Wallis ANOVA.

\section{Results}

In vivo PHTN in wild-type and eNOS ${ }^{-1-}$ mice. We tested the effect of hypoxia on RV pressure in vivo at three levels of inspired $\mathrm{O}_{2}$ : sea level (inspired $\mathrm{PO}_{2}=150 \mathrm{mmHg}$ ), 5,280 $\mathrm{ft}$ (inspired $\mathrm{PO}_{2}=122 \mathrm{mmHg}$ ), and 17,000 ft (inspired $\mathrm{PO}_{2}=76 \mathrm{mmHg}$ ). Results of $\mathrm{RV}$ systolic pressure measurements are shown in Fig. 1. eNOS ${ }^{-/-}$mice demonstrated enhanced sensitivity to hypoxia, manifest by significant PHTN at Denver's altitude. Because the mice studied after severe hypoxia were four weeks older than the other groups, we studied the effect of aging on RV pressures in vivo. There was no additional increase in RV pressure in wild-type or eNOS ${ }^{-/-}$mice at age 10 weeks compared with six weeks in mild hypoxia (32.81 \pm 3.05 vs. $31.42, P=$ not significant [ns], $n=4$ and 8 in wild-type; $41.93 \pm 1.5$ vs. $41.84 \pm 0.87, P=$ ns, $n=4$ and 5 in $\mathrm{eNOS}^{-/-}$). Despite this enhanced sensitivity, the majority of hypoxic PHTN was seen in $\mathrm{eNOS}^{-/-}$mice raised at $5,280 \mathrm{ft}$, with little additional increase seen with exposure to more severe hypoxia. This contrasted with control mice, which developed little PHTN when raised at $5280 \mathrm{ft}(P=0.078)$, but comparable PHTN to eNOS ${ }^{-/}$ mice during exposure to more severe hypoxia.

Time course of development of bypoxic PHTN. We studied the time course for development of PHTN in eNOS $\mathrm{N}^{-/}$ and control mice during exposure to severe hypoxia. As Fig. 2 shows, control mice developed PHTN nearly as severe as that of $\mathrm{eNOS}^{-/-}$mice, reaching a new steady state within two weeks of exposure to an altitude of $17,000 \mathrm{ft} . \mathrm{eNOS}^{-/-}$mice demonstrated a much smaller increase in RV systolic pressure after two weeks of severe hypoxia that did not significantly increase further after an additional two weeks of exposure.

$R V$ bypertrophy. Measurements of RV mass were consistent with the development of PHTN (Table 1). The RV/LV $+\mathrm{S}$ ratio in $\mathrm{eNOS}^{-/-}$mice raised at sea level did not differ from that of wild-type controls. The $\mathrm{RV} / \mathrm{LV}+\mathrm{S}$ ratio in $\mathrm{eNOS}^{-/-}$mice raised at $5,280 \mathrm{ft}$ was significantly greater than that of wild-type controls. In mice exposed to four weeks of severe hypoxia, $\mathrm{RV} / \mathrm{LV}+\mathrm{S}$ was elevated in both groups and tended to be greater in $\mathrm{eNOS}^{-/-}$mice compared with wild-type controls. Because of the relative decreased body weights of animals exposed to hypoxia, we also compared RV mass/body weight ratios. As in

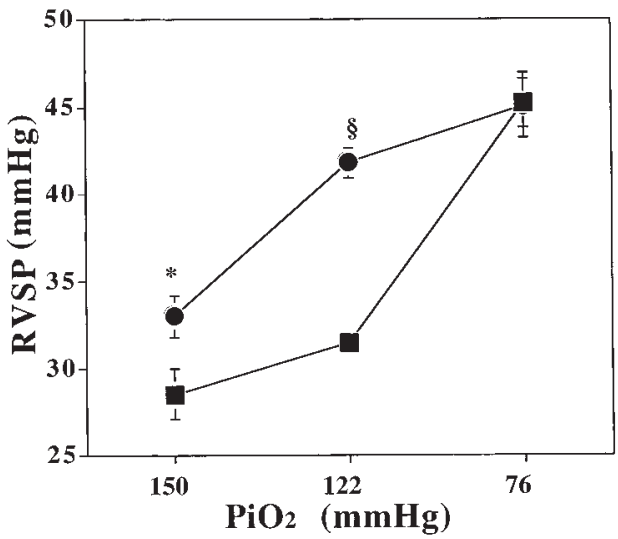

\section{Figure 1}

Right ventricular systolic pressure (RVSP; mean \pm SEM) as an estimate of pulmonary artery systolic pressure in eNOS-/- (closed circles) vs. control $(+/+)$ (closed squares) mice measured after exposure to conditions equivalent to sea level $\left(\mathrm{PiO}_{2}=150 \mathrm{mmHg}\right), 5,280$-ft elevation $\left(\mathrm{PiO}_{2}=122\right.$ $\mathrm{mmHg}$ ), and $17,000-\mathrm{ft}$ elevation $\left(\mathrm{PiO}_{2}=76 \mathrm{mmHg}\right)$. eNOS ${ }^{-/}$mice had mildly increased pulmonary pressures at sea-level conditions $\left({ }^{*} P=0.013\right.$; $n=6$ and 9 , respectively) and pronounced pulmonary hypertension at modest hypoxia $(5,280$-ft elevation) $(\$ P<0.0001 ; n=6$ and 8 , respectively). Severe hypoxia results in similar degrees of pulmonary hypertension in $\mathrm{eNOS}^{-/-}$and control mice ( $P=\mathrm{ns} ; n=7$ and 8 , respectively). eNOS, endothelial nitric oxide synthase.

Table 1, there was no difference in the RV/body weight ratios in wild-type or $\mathrm{eNOS}^{-/-}$mice in normoxia. There was a trend for increased RV mass/body weight ratio in eNOS $^{-/}$mice in mild and severe hypoxia. Additionally, because of the presence of systemic hypertension in $\mathrm{eNOS}^{-/-}$mice, we measured LV mass, finding no difference in LV weight compared with body mass between wild-type and eNOS ${ }^{-/-}$mice (Table 1).

Arterial blood gases, hematocrit, and systemic bypertension. Arterial blood gas values did not differ between the two groups at any level of hypoxia (Table 2). Hematocrits were

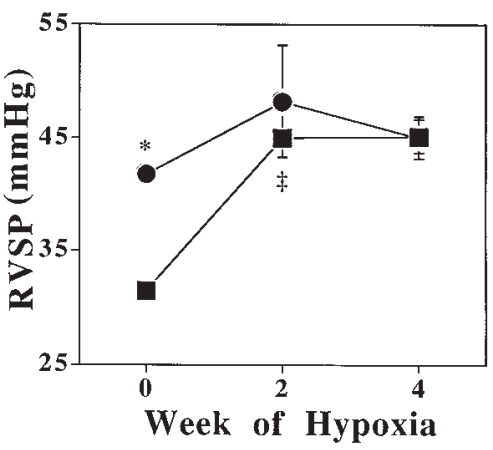

\section{Figure 2}

Right ventricular systolic pressure (RVSP; mean $\pm \mathrm{SEM})$ in $\mathrm{eNOS}^{-/-}$(closed circles) and control $(+/+)$ (closed squares) mice at baseline in mild hypoxia ( $n=6$ and 8 , respectively), and after 2 and 4 weeks of severe, sustained hypoxia ( $n=4$ and $5 ; 7$ and 8 , respectively). At baseline, eNOS ${ }^{-1-}$ mice had significantly increased right ventricular pressures $\left({ }^{*} P<0.0001\right)$. eNOS ${ }^{-/-}$mice had a small increase in pulmonary pressure at 2 weeks of hypoxia that did not increase further. Pulmonary pressure in control mice increased to the same levels as eNOS ${ }^{-/-}$mice by 2 weeks of hypoxia $(\ddagger P<$ $0.001)$ and did not increase further after 2 additional weeks. 
a

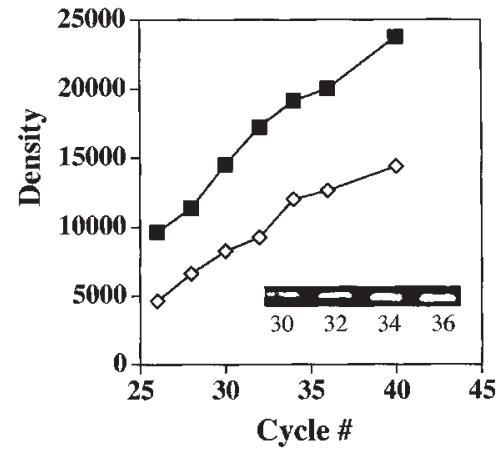

$\boldsymbol{b}$

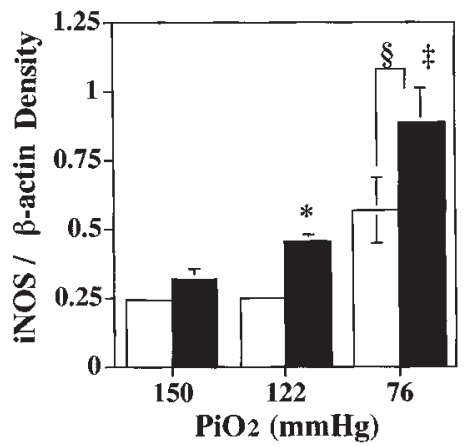

Figure 3

Semiquantitative RT-PCR. (a) PCR product density over a range of cycle number for both iNOS (open diamonds) and $\beta$-actin (closed squares). Inset: Intensity of iNOS PCR products increased with increasing cycle number. ( $\boldsymbol{b}$ ) Relative density of iNOS/ $\beta$-actin PCR products from wild-type (open bars) and eNOS ${ }^{-/}$(closed bars) (mean \pm SEM) mice at differing degrees of oxygen exposure, demonstrating increased iNOS mRNA in eNOS ${ }^{--}$compared with controls in mild hypoxia $\left({ }^{*} P=0.01\right)$ and after severe hypoxia $\left({ }^{\ddagger} P<0.05\right)$. Both wild-type and eNOS mice had increased iNOS after severe hypoxia compared with like mice at either normoxia or mild hypoxia ( $\$ P=0.001, n=3$ in each group). $R T$, reverse transcriptase.

increased in both wild-type and $\mathrm{eNOS}^{-/-}$mice at mild hypoxia compared with normoxia (Table 3). Hematocrits were further increased in wild-type and $\mathrm{eNOS}^{-/-}$mice after severe hypoxia compared with both normoxia and mild hypoxia. There was a small increase in the hematocrit in $\mathrm{eNOS}^{-1-}$ compared with that of control mice at severe hypoxia. Consistent with prior reports in $\mathrm{eNOS}^{-/-}$mice, we found systemic blood pressure was elevated in eNOS ${ }^{-/-}$ mice compared with controls. Under normoxic conditions, LV systolic pressure was elevated in $\mathrm{eNOS}^{-/-}$mice (142.1 \pm 5.64 vs. $107.8 \pm 7, P<0.01, n=6$ and 5$)$. $\mathrm{eNOS}^{-/-}$mice also had increased LV systolic pressures in mild hypoxia (163.7 \pm 7.6 vs. $126.1 \pm 3.6, P<0.01, n=4$ and 7 ) and severe hypoxia $(134.86 \pm 2.31$ vs. $119 \pm 4.23, P<0.01, n=8$ and 5$)$. Despite elevated LV systolic pressure at 5,280 ft, LV end diastolic pressure did not differ between $\mathrm{eNOS}^{-/-}$and control mice $(4.9 \pm 2.7$ vs. $5.2 \pm 2.6 \mathrm{mmHg}, P=\mathrm{ns}, n=6)$.

Expression of other NOS isoforms. To determine whether mRNA for other NOS isoforms was induced in $\mathrm{eNOS}^{-/}$ and wild-type mice during hypoxic exposure, semiquantitative RT-PCR was performed on lungs from $\mathrm{eNOS}^{-/-}$and control mice. Figure 3 demonstrates that steady-state iNOS mRNA was greater in lungs from $\mathrm{eNOS}^{-/}$mice compared with wild-type controls raised in mild hypoxia $(P=$
$0.01)$ and following severe hypoxia $(P<0.05)$. Severe hypoxia was also associated with an increase in iNOS message in both control and $\mathrm{eNOS}^{-/-}$mice compared with like mice in normoxia or mild hypoxia $(P=0.001)$. In contrast, no increase in nNOS message was found (data not shown).

Vascular remodeling. To evaluate the effect of loss of eNOS on pulmonary vascular structure, lungs from $\mathrm{eNOS}^{-/}$ mice and wild-type mice were evaluated for the presence of muscularization of the small vessels. As Fig. 4 demonstrates, there was a twofold increase in the proportion of fully muscularized vessels in $\mathrm{eNOS}^{-/-}$mice compared with controls with decreasing $\mathrm{PiO}_{2}$. In contrast, there was no difference in medial thickness or vessel number between wild-type and eNOS-deficient mice exposed to normoxia, mild hypoxia, or severe hypoxia (data not shown).

Effect of inhaled NO. To determine whether a component of the PHTN seen in eNOS ${ }^{-/-}$mice was due to sustained vasoconstriction, we tested the ability of inhaled NO $(25$ ppm for five minutes) to reverse PHTN in six-week-old $\mathrm{eNOS}^{-/-}$mice raised in Denver breathing room air. As Fig. 5 shows, NO completely reversed the PHTN. The effect of inhaled $\mathrm{NO}$ on wild-type mice raised in Denver was also tested, and a small, although nonsignificant, reduction in RV systolic pressure was seen. Inhaled NO

Table 1

Right ventricular hypertrophy in wild-type and eNOS ${ }^{-1-}$ mice exposed to differing degrees of hypoxia

\begin{tabular}{|c|c|c|c|c|c|c|}
\hline Mouse & $n$ & $\mathrm{PiO}_{2}$ & $\mathrm{RV} / \mathrm{LV}+\mathrm{S}$ & BW & $\mathrm{RV} / \mathrm{BW}$ & $\mathrm{LV} / \mathrm{BW}$ \\
\hline \multirow[t]{3}{*}{ Wild-type } & 5 & 150 & $0.304 \pm 0.022$ & $21.6 \pm 0.91$ & $0.09 \pm 0.006$ & $0.303 \pm 0.022$ \\
\hline & 6 & 122 & $0.243 \pm 0.014$ & $21.6 \pm 0.78$ & $0.09 \pm 0.009$ & $0.355 \pm 0.007$ \\
\hline & 5 & 76 & $0.325 \pm 0.015$ & $23.5 \pm 0.76$ & $0.12 \pm 0.013$ & $0.33 \pm 0.018$ \\
\hline \multirow[t]{3}{*}{$\mathrm{eNOS}^{-/-}$} & 8 & 150 & $0.285 \pm 0.01$ & $20.5 \pm 0.56$ & $0.09 \pm 0.003$ & $0.326 \pm 0.009$ \\
\hline & 7 & 122 & $0.346 \pm 0.03^{\mathrm{A}}$ & $19.4 \pm 0.69^{A}$ & $0.12 \pm 0.027$ & $0.355 \pm 0.007$ \\
\hline & 5 & 76 & $0.374 \pm 0.029$ & $20.2 \pm 0.35^{A}$ & $0.14 \pm 0.016$ & $0.362 \pm 0.027$ \\
\hline \multirow[t]{3}{*}{$\mathrm{eNOS}^{+/-}$} & 5 & 150 & $0.295 \pm 0.016$ & $20.08 \pm 0.83$ & $0.118 \pm 0.01$ & $0.331 \pm 0.013$ \\
\hline & 14 & 122 & $0.317 \pm 0.013^{A}$ & $24.17 \pm 0.76^{\mathrm{A}, \mathrm{B}}$ & $0.108 \pm 0.01$ & $0.323 \pm 0.008^{\mathrm{B}}$ \\
\hline & 4 & 76 & $0.375 \pm 0.024$ & $25.5 \pm 1.31^{\mathrm{B}}$ & $0.098 \pm 0.007$ & $0.262 \pm 0.01^{\mathrm{A}, \mathrm{B}}$ \\
\hline
\end{tabular}

Increased right ventricular $(R V)$ mass in eNOS $-/$ and eNOS + - mice compared with controls by relationship to left ventricular $(L V)$ mass $(R V / L V+S)$ or body weight $(R V / B W)$. Left ventricular mass related to body weight $(L V / B W) .{ }^{{ }^{A}} P<0.05$ compared with wild-type at same altitude (mean $\left.\pm S E M\right) .{ }^{\text {E } P<0.05 ~ c o m p a r e d ~ w i t h ~}$ eNOS ${ }^{-i-}$ at same altitude (mean \pm SEM). 
$a$

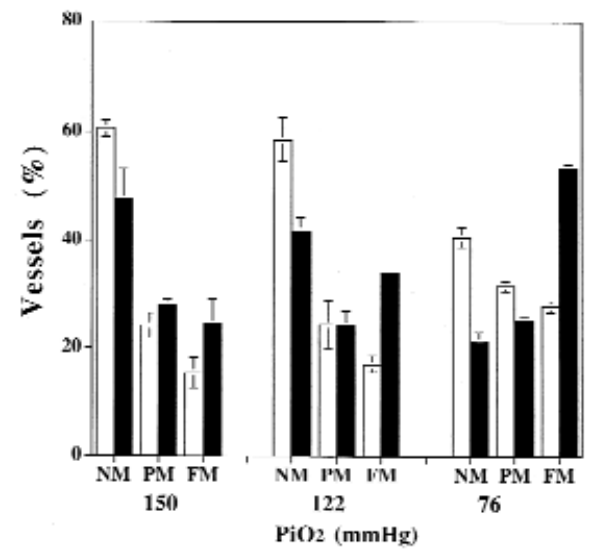

Figure 4

(a) Distribution of nonmuscular, partially muscular, and fully muscularized small arterioles (mean \pm SEM) in wild-type (open bars) and eNOS ${ }^{-1-}$ (closed bars) mice at differing levels of hypoxia, demonstrating that with decreasing $\mathrm{PiO}_{2}$ there is a twofold increase in the percentage of fully muscularized (FM) small vessels in eNOS ${ }^{-1-}$ vs. wild-type mice $(P=0.012)$. Additionally, there is a greater decrease in the nonmuscular $(N M)$ arteries in eNOS $-/-$ mice compared with wild-type with decreasing $\mathrm{PiO}_{2}(P=0.018)$. There is a trend for increased partially muscularized $(P M)$ arterioles in eNOS ${ }^{-/-}$mice compared with wild-type with decreasing $\mathrm{PiO}_{2}(P=0.11) .(P<0.05$ significant by Kruskal-Wallis ANOVA). (b) Photomicrographs $(\times 40)$ of myosin-stained lung sections of (1) wild-type lung in normoxia demonstrating a nonmuscular vessel, (2) wild-type lung after severe hypoxia with a partially muscularized vessel, and (3) eNOS- - lung after severe hypoxia with a fully muscularized vessel. $A D$, alveolar ducts. $b$

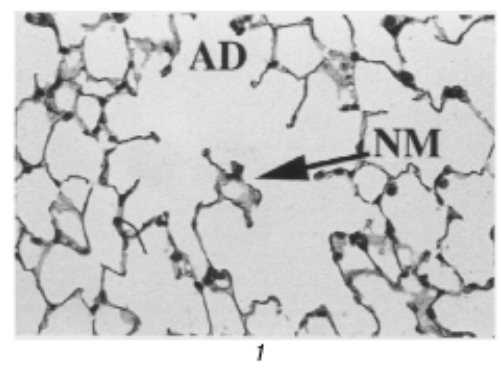

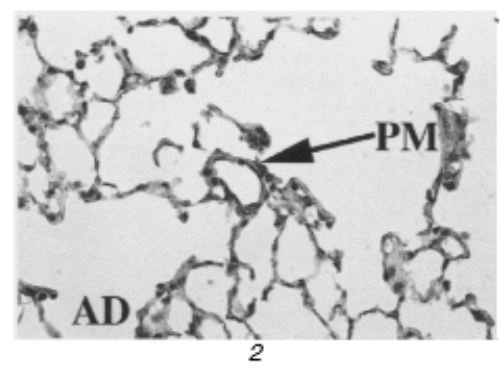

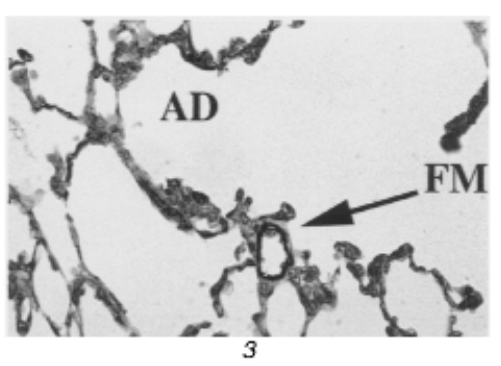

was also administered to four $\mathrm{NOSS}^{-/-}$mice aged five to six months. Complete reversal of PHTN was again seen (41.84 \pm 0.87 vs. $30.98 \pm 0.3, P<0.05$ ).

Hemodynamics of $\mathrm{NOS}^{+/-}$mice. We questioned whether there was a dose-effect to the loss of eNOS on the response to hypoxia. To do so, we bred mice heterozygous at the eNOS allele (eNOS $\left.{ }^{+/-}\right)$. This yielded one functional eNOS allele, and Western blot analysis demonstrated $48 \pm 13 \%$ of eNOS protein in heterozygote lung compared with control (Fig. $6 ; P=0.06, n=3$ ). With exposure to hypoxia, eNOS ${ }^{+/}$mice demonstrated a phenotype that was indistinguishable from $\mathrm{eNOS}^{-/-}$mice, with significant PHTN seen at 5,280-ft elevation relative to either sea-level values or those of wild-type mice raised at 5,280 ft (Fig. 7). Similarly, RV hypertrophy in $\mathrm{eNOS}^{+/-}$ mice was indistinguishable from $\mathrm{eNOS}^{-/-}$mice (Table 1). Measurements of $L V$ pressure at 5,280 ft demonstrated a phenotype intermediate to $\mathrm{eNOS}^{-/-}$mice and control mice (LV systolic: $163.7 \pm 7.6$ in $\mathrm{eNOS}^{-/-}$mice $[n=4] ; 139$ $\pm 3.2 \mathrm{mmHg}$ in $\mathrm{eNOS}^{+/-}$mice $[n=3]$ vs. $126.6 \pm 3.6$ $\mathrm{mmHg}$ in control mice $[P=0.03, n=3])$.

\section{Discussion}

Our studies tested the role of EDNO in modulating the pulmonary vascular response to chronic hypoxia. To establish a baseline, we first assessed the effect of EDNO on the pulmonary circulation of animals maintained in normoxia since birth by exposing mice to sea-level barometric pressure for the first six weeks of life and then measuring RV systolic pressure. We found that loss of eNOS produced only minimal PHTN under normoxic conditions. The approximately $17 \%$ elevation in RV systolic pressure that we observed was similar in magnitude to that reported by Steudel et al. (21) in eNOS ${ }^{-1-}$ mice raised at sea level, measured by direct pulmonary artery
(PA) catheterization in open-chest, deeply anesthetized, paralyzed animals. While the relative increase in PA systolic pressure was comparable, the absolute value of RV pressure measured in our study was approximately twice that observed by Steudel et al. The most likely explanation for this discrepancy is our use of lightly anesthetized, spontaneously breathing, closed-chest animals, in which the measured RV pressure more closely approximates that in the conscious animal. Despite these methodological differences, our studies taken together suggest that while eNOS plays a role in modulating the normally low tone of the pulmonary circulation, loss of EDNO by itself is not sufficient to produce physiologically significant PHTN in normoxic animals.

We next questioned whether development of PHTN in response to chronic hypoxia would be aggravated in $\mathrm{eNOS}^{-/}$mice. Denver's altitude of $5,280 \mathrm{ft}$, with an inspired $\mathrm{PO}_{2}$ of $122 \mathrm{mmHg}$, is generally believed to be

\section{Table 2}

Arterial blood gas measurements from wild-type and control mice chronically exposed to differing degrees of hypoxia measured while breathing oxygen similar to the chronic $\mathrm{PiO}_{2}$

\begin{tabular}{lcccc}
\hline Mouse & $\begin{array}{c}\mathrm{FiO}_{2} \% / \mathrm{PiO}_{2} \\
(\mathrm{mmHg})\end{array}$ & $n$ & $\begin{array}{c}\mathrm{PO}_{2} \\
(\mathrm{mmHg})\end{array}$ & $\begin{array}{c}\mathrm{PCO}_{2} \\
(\mathrm{mmHg})\end{array}$ \\
Wild-type & $0.25 / 145$ & 3 & $102 \pm 10.02$ & $27.67 \pm 1.2$ \\
& $0.21 / 122$ & 4 & $62.25 \pm 2.4$ & $34.25 \pm 3.15$ \\
& $0.11 / 64$ & 4 & $45.5 \pm 4.35$ & $24.5 \pm 1.5$ \\
eNOS $^{-1-}$ & $0.25 / 145$ & 3 & $104.7 \pm 15.1$ & $30.67 \pm 0.88$ \\
& $0.21 / 122$ & 5 & $68 \pm 3.54$ & $35 \pm 1.3$ \\
& $0.11 / 64$ & 4 & $43.25 \pm 2.98$ & $28.5 \pm 3.66$
\end{tabular}

Arterial oxygen and carbon dioxide tensions in wild-type and eNOS ${ }^{-1-}$ mice breathing oxygen concentrations similar to their chronic exposure are not different between the two groups (mean \pm SEM). 


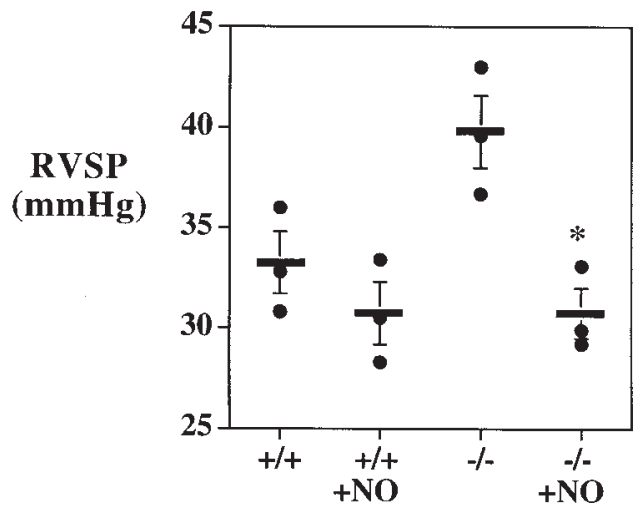

Figure 5

Right ventricular systolic pressure (RVSP) in wild-type (+/+) and eNOS (-/-) mice raised at an altitude of $5280 \mathrm{ft}$ breathing room air or room air with 25 ppm of nitric oxide demonstrating a small, nonsignificant decrease in right ventricular pressures in wild-type mice ( $P=\mathrm{ns}, n=3)$ but reversal of the pulmonary hypertension in $\mathrm{eNOS}^{-/}$mice $\left({ }^{*} P=0.003, n=3\right)$. Bar, mean $\pm \mathrm{SEM}$.

innocuous, and it does not produce significant PHTN in otherwise normal humans or other species. However, when $\mathrm{RV}$ systolic pressure was measured in $\mathrm{eNOS}^{-/-}$mice raised for six weeks at Denver's altitude, we found significant PHTN. This was associated with elevated RV mass, confirming the presence of chronic elevation in PA pressure. We excluded excessive polycythemia, LV failure, and hypoxemia in $\mathrm{eNOS}^{-/-}$mice as causes of hypoxic PHTN. Thus, we conclude that enhanced hypoxic vasoconstriction most likely accounted for the increased pulmonary pressures seen in $\mathrm{eNOS}^{-/-}$mice raised in Denver.

Because NO also exerts an antiproliferative effect on vascular smooth muscle cells, we questioned whether augmented PA muscularity contributed to the development of hypoxic PHTN in $\mathrm{eNOS}^{-/}$mice (26). We observed that the degree of fully muscularized small vessels was increased in $\mathrm{eNOS}^{-/-}$mice compared with controls raised in mild hypoxia. Although suggestive of some minimal degree of vascular remodeling, there was little evidence of additional PA remodeling, raising the possibility that constriction of these newly muscularized arteries, rather than physical encroachment, was the predominant abnormality in $\mathrm{eNOS}^{-/-}$mice. To determine the role of vasoconstriction, we tested the effect of inhaled $\mathrm{NO}$ on $\mathrm{RV}$ pressure. We reasoned that if the principal effect of

Table 3

Hematocrits in wild-type and eNOS ${ }^{-/-}$mice exposed to differing degrees of hypoxia

\begin{tabular}{lllc}
\hline Mouse & $\mathrm{PiO}_{2}$ & $n$ & Hematocrit (\%) \\
Wild-type & 150 & 5 & $36.1 \pm 0.81$ \\
& 122 & 6 & $45.17 \pm 0.28^{\mathrm{A}}$ \\
& 76 & 5 & $55.3 \pm 1.42^{\mathrm{A}, \mathrm{B}}$ \\
eNOS $^{-i-}$ & 150 & 9 & $36.94 \pm 0.85$ \\
& 122 & 7 & $44.5 \pm 1.58^{\mathrm{A}}$ \\
& 76 & 6 & $59.25 \pm 1.1^{\mathrm{A}-\mathrm{C}}$
\end{tabular}

Increased hematocrits in wild-type and eNOS- $/$ - mice exposed to hypoxia. ${ }^{A} P<0.05$ compared with $\mathrm{PiO}_{2}=150$ (mean \pm SEM). ${ }^{\mathrm{B}} \mathrm{P}<0.05$ compared with $\mathrm{PiO}_{2}=122$ (mean $\pm \mathrm{SEM}) .{ }^{C} P<0.05$ compared with wild-type at same $\mathrm{PiO}_{2}($ mean $\pm \mathrm{SEM})$. the loss of EDNO was vasoconstriction, then acute inhaled NO would significantly reduce RV pressure. If, alternatively, luminal narrowing due to vascular remodeling was the primary contributor, then acute inhaled NO would be relatively ineffective. Consistent with a central role for vasoconstriction, we found that inhaled NO completely reversed PHTN. While it is possible that with longer observation, $\mathrm{eNOS}^{-/-}$mice might have developed more significant pulmonary vascular remodeling, inhaled NO studies were also performed using mice as old as six months of age with similar results, suggesting that in the mouse, little fixed structural change occurs.

Two recent studies $(19,20)$ reported that $\mathrm{eNOS}^{-/-}$mice had markedly enhanced systemic vascular remodeling in response to injury. Our finding that the pulmonary circulation of eNOS ${ }^{-/-}$mice displayed only modest remodeling of distal vessels in response to hypoxia suggests that hypoxia may, by itself, produce an insufficient degree of injury to stimulate medial hypertrophy of more proximal vessels. We also failed to detect significant medial hypertrophy or vessel rarefaction in the lungs of either wild-type or eNOS $^{-/-}$mice exposed to more severe hypoxia. This result differs from an earlier report by Hales et al. (27), who found an approximate twofold increase in PA medial thickness and a $50 \%$ reduction in arterial density in chronically hypoxic mice. The reason for this difference is uncertain. One possibility is a strain difference, as BALB/c mice were used in the prior study and C57BL6/SV129 mice in the present one. Alternatively, methodological differences, such as the use of hypobaric hypoxia in our study versus nitrogen dilution in the prior one, may be important. Given the relatively subtle PA remodeling in C57BL6/SV129 mice, it is possible that the loss of EDNO in other strains of mice or other species would result in more prominent remodeling than that seen in our study.

Chronic hypoxic PHTN in animals is conventionally studied by exposure to inspired $\mathrm{O}_{2}$ concentration of $10 \%-12 \%$, equivalent to approximately $17,500-\mathrm{ft}$ elevation. In the past, studies of rats treated with the NOS inhibitor LNAME (nitro-L-arginine methyl ester) failed to reveal augmented chronic hypoxic PHTN under those conditions (16). However, those studies were complicated by significant reductions in cardiac output, confounding the interpretation of PA pressure. We exposed $\mathrm{eNOS}^{-/}$mice to 17,000-ft elevation for up to four weeks, measuring RV systolic pressure sequentially. In contrast to the result at Denver's $\mathrm{PO}_{2}$, more severely hypoxic eNOS ${ }^{-/-}$mice did not develop more significant PHTN than did wild-type controls. This is in contrast to Steudel et al. (22), who observed that $\mathrm{NOS}^{-/-}$ mice had a $25 \%$ greater increase in RV pressure after exposure to $\mathrm{FiO}_{2}=11 \%$ for three weeks than did wild-type controls. This discrepancy may be due to methodological differences between the two studies. In this study, mice were spontaneously breathing and not exposed to hyperoxia. In the study by Steudel et al., mice were mechanically ventilated with $\mathrm{FiO}_{2}=80 \%$, which may have augmented NO production and lowered RV pressure in wild-type mice. In addition, our wild-type control mice were 129SV/BL6 cross, reflecting the same background as the $\mathrm{eNOS}^{-/-}$mice rather than the 129SV mice used by Steudel et al.

Measurements of LV end diastolic pressure were normal at the time of sacrifice, suggesting relatively normal 
cardiac function. In addition, we monitored LV contractility serially using transthoracic ultrasound and detected no significant reduction in function (data not shown) compared with wild-type controls under the same conditions. Thus, our study, while eliminating the confounding effects of L-NAME in the prior report, found a similar result, suggesting that EDNO does not play a major role in modulating the development of hypoxic PHTN during severe, sustained hypoxia.

These findings must be reconciled with a growing body of evidence suggesting that eNOS protein is induced in the pulmonary circulation of chronically hypoxic animals. Several studies of adult rats exposed to hypoxia found increased eNOS protein and activity, and hypertensive lungs from chronically hypoxic rats have been shown to produce significantly more NO than do lungs form normoxic rats $(11,12)$. This apparent paradox suggests that in the rat, either NO becomes an ineffective pulmonary vasodilator at low $\mathrm{PO}_{2}$, or eNOS, although present in increased amounts, produces insufficient NO to oppose chronic HPV. The former possibility is not likely, because inhaled NO is extremely effective in reversing hypoxic PHTN (28). Therefore, it is most likely that chronic hypoxia interferes with eNOS activity, thus reducing production of endogenous EDNO. In support of that hypothesis, we have recently found that when ventilated with hypoxic gas, NOx measured in lung perfusate in vitro, and plasma in vivo, from chronically hypoxic rats is not increased when compared with normoxic, normotensive control animals (29). Nelin et al. (30) found that acute hypoxic ventilation of neonatal porcine lungs reduced perfusate $\mathrm{NOx}$ production to a similar degree as did pharmacologic NOS inhibition. In addition, the induction of eNOS by hypoxia could be species-specific and developmentally regulated, because studies of neonatal PHTN in lambs and piglets found a significant reduction in eNOS protein (31-33).

In this study, we found no difference in PHTN between eNOS $^{-/}$and wild-type mice after exposure to severe hypoxia. At the same time, we observed an increase in iNOS message in $\mathrm{eNOS}^{-/-}$mice compared with controls in mild hypoxia. iNOS message was further augmented by exposure to hypobaric hypoxia in both wild-type and $\mathrm{eNOS}^{-/-}$mice. iNOS protein has recently been reported to be increased in $\mathrm{eNOS}^{-/-}$and chronically hypoxic mice (34). These findings suggest that while EDNO may not be increased in hypoxia, other sources of NO may act to compensate and limit the degree of PHTN in the mouse resulting from chronic severe hypoxia.

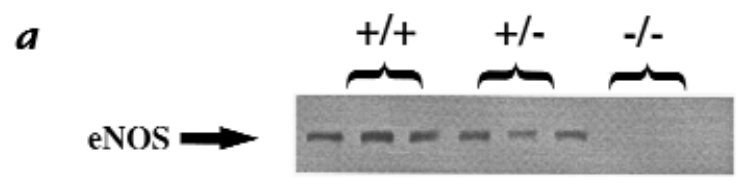

$b$

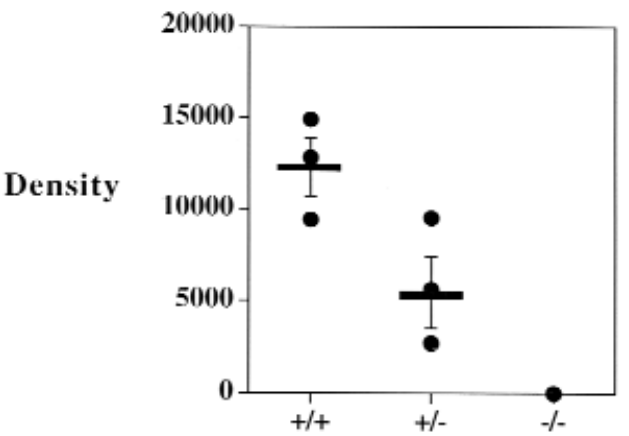

Figure 6

Western blot analysis of lung homogenates from wild-type (+/+), eNOS $(-/-)$, and eNOS heterozygous (+/-) mice. (a) Western blot. No protein was detectable in eNOS ${ }^{-/-}$mice, whereas eNOS ${ }^{+/-}$mice had $48 \pm 13 \%$ of eNOS protein expression compared with controls $(\boldsymbol{b})(n=3, P=0.06)$. $\mathrm{Bar} /$ mean $\pm \mathrm{SEM}$.

$\mathrm{eNOS}^{-/-}$mice are a useful experimental system with which to test the role of EDNO in modulating pulmonary vascular responses to hypoxia. However, whether eNOS is ever deficient in the pulmonary circulation of humans is controversial. Giaid et al. (35) found that eNOS immunostaining was significantly decreased in lungs from humans with chronic PHTN. The loss was most pronounced in lungs from patients with primary PHTN and in those with the greatest degree of PHTN. That study could not determine whether the loss of eNOS preceded the development of PHTN or vice versa. Whether the loss of eNOS occurs in all patients with PHTN is uncertain and has been questioned by other investigators (36). The possibility that altered regulation of eNOS could be associated with vascular pathology is also suggested by a preliminary report suggesting that polymorphisms in the eNOS promoter are associated with reduced eNOS gene transcription and coronary vasospasm (37). Therefore, it is likely that reduced eNOS expression can be associated with vascular pathology in both the pulmonary and systemic circulations.

We reasoned that while the complete loss of eNOS is

\begin{abstract}
Figure 7
Right ventricular systolic pressure (RVSP; mean $\pm \mathrm{SEM}$ ) in wild-type (open bars), eNOS ${ }^{+/-}$(shaded bars) mice, and eNOS ${ }^{-/-}$(closed bars) mice exposed to inspired $\mathrm{O}_{2}$ equivalent to sea level, mild hypoxia, and severe hypoxia. There was a modest increase in $\mathrm{RV}$ systolic pressure in $\mathrm{eNOS}^{+/-}$and ${ }^{-/-}$mice compared with controls ( ${ }^{*} P=0.01$ for each) in normoxia, but they did not differ from one another ( $P=\mathrm{ns} ; n=6,9$, and 5 , respectively). After exposure to mild hypoxia, RV systolic pressure was similar in $\mathrm{eNOS}^{+/-}$and ${ }^{-/-}$mice $(P=$ $\mathrm{ns})$ and significantly higher than in wild-type mice $(\ddagger P<0.001, n=14,5$, and 8 , respectively). After exposure to severe hypoxia, control mice $(n=8)$ had a significant increase in $\mathrm{RV}$ pressure $(P<0.001)$ compared with 5,280 ft. eNOS $-/-$ mice had a small increase in RV pressure compared with 5,280 ft $(P=0.12, n=7)$. $\mathrm{eNOS}^{+/-}$mice $(n=6)$ also had an increase in RV pressure $(P<0.01)$ compared with $5,280 \mathrm{ft}$ after exposure to severe hypoxia. However, there was no difference between the mice after severe hypoxia.
\end{abstract}

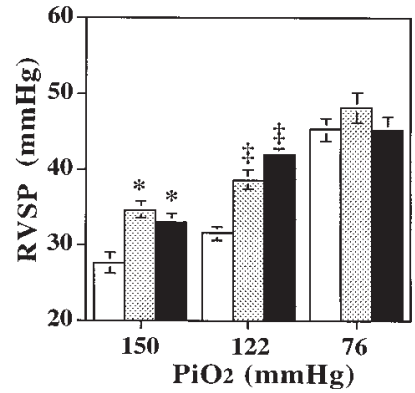


unlikely to occur in humans as either an acquired or genetic condition, partial loss could occur and have physiological consequences. Therefore, to model this condition, we bred mice that were heterozygous for the loss of eNOS by mating $\mathrm{eNOS}^{-/-}$mice with wild-type, strainmatched mice. These mice had normal fertility and produced offspring that were obligate heterozygotes. Western blot analysis confirmed a 50\% reduction in eNOS protein in the lungs of the $\mathrm{eNOS}^{+/-}$mice when studied at six to eight weeks of age. Measurement of RV pressure in those mice demonstrated a phenotype that was indistinguishable from mice completely deficient in eNOS at the three levels of alveolar $\mathrm{PO}_{2}$ studied. Thus, it appears that even a $50 \%$ loss of eNOS protein is sufficient to produce significant augmentation in pulmonary vascular sensitivity to hypoxia, in vivo. This finding is consistent with the report in neonatal sheep, demonstrating a $50 \%$ reduction in eNOS protein in lambs with PHTN resulting from intrauterine ductal ligation (38). In this study, the loss of eNOS was acquired and a cause-effect relationship could not be proved, whereas in our study, the loss of eNOS was genetic and the primary cause of increased susceptibility of the pulmonary circulation to mild hypoxia.

We also found increased systemic pressure in $\mathrm{eNOS}^{+/-}$ mice, although, in contrast to the pulmonary circulation, the systemic hypertension was intermediate between wild-type and eNOS ${ }^{-/-}$mice. The vascular phenotype of $\mathrm{eNOS}^{+/-}$mice, in vivo, has not been reported previously. However, Faraci et al. (39) recently reported reduced maximal endothelium-dependent relaxation in carotid artery rings from $\mathrm{eNOS}^{+/-}$mice, in vitro. The finding that even the heterozygote $\mathrm{eNOS}^{+/-}$mice have a prominent vascular phenotype is unique. In general, the loss of one allele of any gene has little biologic consequence. However, for the eNOS gene, it appears that there is no compensatory overexpression by the remaining allele and that even a $50 \%$ reduction in protein results in insufficient production of EDNO to oppose vasoconstriction. This suggests that loss of eNOS, of a magnitude that is likely to be encountered in both acquired and genetic vascular diseases, can be a determinant of both pulmonary and systemic vascular tone.

In summary, our studies demonstrate that eNOS activity is an important determinant of pulmonary vascular responsiveness to chronic hypoxia, in vivo. The effect of eNOS-derived NO appears to be most prominent under modest hypoxic stress and is inconsequential during exposure to more severe hypoxia. Even a loss of $50 \%$ of eNOS protein was sufficient to produce this effect. In the murine pulmonary circulation, the loss of EDNO led to reversible vasoconstriction, with evidence of distal extension of PA muscularization. We speculate that in humans, either genetic or acquired reduction of pulmonary vascular eNOS may significantly exacerbate the development of hypoxic PHTN. If true, altered eNOS expression could explain some of the variability in human pulmonary vascular responses to hypoxia in disease states such as high altitude pulmonary edema, chronic obstructive lung disease, and obstructive sleep apnea.

\section{Acknowledgments}

Assistance from Julie Harrel for histology slide preparation, Maria
Frid for myosin antibodies, Marilee Horan in preparation of Western blot analysis, and Jeff Griebel for inhaled nitric oxide monitoring was greatly appreciated. This work was supported by National Heart, Lung, and Blood Institute grants HL-14985 (to D.M. Rodman and I.F. McMurtry), HL-48038 (to D.M. Rodman), and HL-07085 (to K.A. Fagan), and by American Heart Association grant 96008150. D.M. Rodman was an Established Investigator of the American Heart Association.

1. Cremona, G., Wood, A.M., Hall, L.W., Bower, E.A., and Higenbottam, T. 1994. Effects of inhibition of nitric oxide release on vascular tone in isolated lungs of pig, sheep, dog, and man. J. Physiol. 481:185-195.

2. Blitzer, M.L., Loh, E., Roddy, M.A., Stamler, J.S., and Creager, M.A. 1996. Endothelium-derived nitric oxide regulates systemic and pulmonary vascular resistance during acute hypoxia in humans. J. Am. Coll. Cardiol. 28:591-596.

3. Shirai, M., et al. 1997. Endogenous nitric oxide attenuates hypoxic vasoconstriction of small pulmonary arteries and veins in anesthetized cats. Acta. Physiol. Scand. 159:263-264.

4. Hillier, S.C., et al. 1997. Hypoxic vasoconstriction in pulmonary arterioles and venules. J. Appl. Physiol. 82:1084-1090.

5. Blitzer, M.L., Lee, S.D., and Creager, M.A. 1996. Endothelium-derived nitric oxide mediates hypoxic vasodilation of resistance vessels in humans. Am. J. Physiol. 271:H1182-H1185.

6. Persson, M.G., Gustafsson, L.E., Wiklund, N.P., Moncada, S., and Hedqvist, P. 1990. Endogenous nitric oxide as a probable modulator of pulmonary circulation and hypoxic pressor response in vivo. Acta Physiol. Scand. 140:449-457.

7. Leeman, M., deBeyl, V.Z., Delcroix, M., and Naeije, R. 1994. Effects of endogenous nitric oxide on pulmonary vascular tone in intact dogs. Am. J. Physiol. 266:H2343-H2347.

8. Stamler, J.S., Loh, E., Roddy, M.A., Currie, K.E., and Creager, M.A. 1994. Nitric oxide regulates basal and systemic pulmonary vascular resistance in healthy humans. Circulation. 89:2035-2040.

9. Karamsetty, V.S., MacLean, M.R., McCulloch, K.M., Kane, K.A., and Wadsworth, R.M. 1996. Hypoxic constrictor response in the isolated pulmonary artery from chronically hypoxic rats. Respir. Physiol. 105:85-93.

10. Kantrow, S.P., et al. 1997. Hypoxia inhibits nitric oxide synthesis in isolated rabbit lung. Am. J. Physiol. 272:L1167-L1173.

11. Isaacson, T.C., Hampl, V., Weir, K.E., Nelson, D.F., and Archer, S.L. 1994. Increased endothelium-derived NO in hypertension pulmonary circulation of chronically hypoxic rats. J. Appl. Physiol. 76:933-940.

12. Tyler, R.C., et al. 1996. Variability in endothelial nitric oxide synthase gene expression in hypoxic, monocrotaline, and fawn-hooded hypertensive rat lungs. Circulation. 94:I-647. (Abstr.)

13. Resta, T.C., and Walker, B.R. 1996. Chronic hypoxia selectively augments endothelium-dependent arterial vasodilation. Am. J. Physiol.270:H888-H896.

14. Brashers, V.L., Peach, M.J., and Rose, C.E. 1988. Augmentation of hypoxic pulmonary vasoconstriction in the isolated perfused rat lung by in vitro antagonists of endothelium-dependent relaxation. J. Clin. Invest. 82:1495-1502.

15. Barer G., Emery, C., Stewart, A., Bee, D., and Howard, P. 1993. Endothelial control of the pulmonary circulation in normal and chronically hypoxic rats. J. Physiol. 463:1-16.

16. Hampl, V., Archer, S.L., Nelson, D.D., and Weir, K.E. 1993. Chronic EDRF inhibition and hypoxia. Effects on pulmonary circulation and systemic blood pressure. J. Appl. Physiol. 75:1748-1757.

17. Huang, P.L., et al. 1995. Hypertension in mice lacking the gene for endothelial nitric oxide synthase. Nature. 377:239-242.

18. Shesely, E.G., et al. 1996. Elevated blood pressures in mice lacking endothelial nitric oxide synthase. Proc. Natl. Acad. Sci. USA. 93:13176-13181.

19. Moroi, M., et al. 1998. Interaction of genetic deficiency of endothelial nitric oxide, gender, and pregnancy in vascular response to injury in mice. J. Clin. Invest. 101:1225-1232.

20. Rudic, R.D., et al. 1998. Direct evidence for the importance of endothelium-derived nitric oxide in vascular remodeling. J. Clin. Invest. 101:731-736.

21. Steudel, W., et al. 1997. Pulmonary vasoconstriction and hypertension in mice with targeted disruption of the endothelial nitric oxide synthase (NOS 3) gene. Circ. Res. 81:34-41.

22. Steudel, W., et al. 1998. Sustained pulmonary hypertension and right ventricular hypertrophy after chronic hypoxia in mice with congenital deficiency of nitric oxide synthase 3. J. Clin. Invest. 101:2468-2477.

23. Kramer, M.F., and Coen, D.M. 1994. The polymerase chain reaction. In Current protocols in molecular biology. F.M. Ausubel et al., editors. John Wiley \& Sons. Boston, MA. 15.0.1-15.1.9.

24. LeCras, T.D., Xue, C., Rengasamy, A., and Johns, R.A. 1996. Chronic hypoxia upregulates endothelial and inducible NO synthase gene and protein expression in rat lung. Am. J. Physiol. 14:L164-L170.

25. Hara, A., et al. 1997. [3H]L-NG-nitroarginine binding after transient focal 
ischemia and NMDA-induced excitotoxicity in type I and III nitric oxide synthase null mice. J. Cereb. Blood Flow Metab. 17:515-526.

26. Cornwell, T.L., Arnold, E., Boerth, N.J., and Lincoln, T.M. 1994. Inhibition of smooth muscle cell growth by nitric oxide and activation of cAMPdependent protein kinase by cGMP. Am. J. Physiol. 267:C1405-C1413.

27. Hales, C.A., Kradin, R.L., Brandstetter, R.D., and Zhu, Y.J. 1983. Impairment of hypoxic pulmonary artery remodeling by heparin in mice. Am. Rev. Respir. Dis. 128:747-751.

28. Kouyoumdjian, C., et al. 1994. Continuous inhalation of nitric oxide protects against development of pulmonary hypertension in chronically hypoxic rats. J. Clin. Invest. 94:578-584.

29. Sato, K., Rodman, D.M., and McMurtry, I.F. 1998. Hypoxia inhibits nitric oxide (NO) production in chronically hypoxic hypertensive rat lungs. FASEB J. 12:A493. (Abstr.)

30. Nelin, L.D., Thomas, C.J., and Dawson, C.A. 1996. Effect of hypoxia on nitric oxide production in neonatal pig lung. Am J. Physiol. 271:H8-H14.

31. Scarborough, J.E., et al. 1998. The role of endothelial nitric oxide expression in the development of pulmonary hypertension in chronically hypoxic infant swine. J. Thorac. Cardiovasc. Surg. 115:343-348.

32. Hislop, A.A., et al. 1997. Endothelial nitric oxide synthase in hypoxic newborn pulmonary vessels. Arch. Dis. Child Fetal Neonatal Ed. 77:F16-F22.
33. Shaul, P.W., III, et al. 1997. Pulmonary endothelial NO synthase gene expression is decreased in fetal lambs with pulmonary hypertension. Am. J. Physiol. 272:L1005-L1012.

34. Quinlan, T.R., Laubach, V., Zhou, N., and Johns, R.A. 1998. Alterations in nitric oxide synthase isoform expression in NOS knockout mice exposed to normoxia or hypoxia. Chest. 114:53S-55S.

35. Giaid, A., and Saleh, D. 1995. Reduced expression of endothelial nitric oxide synthase in the lungs of patients with pulmonary hypertension. $N$. Engl. J. Med. 333:214-222.

36. Xue, C., and Johns, R.A. 1995. Endothelial nitric oxide synthase in the lungs of patients with pulmonary hypertension. N. Engl. J. Med. 333:1642-1644.

37. Nakayama, M., et al. 1997. A T-786 C mutation reduces promoter activity in the endothelial nitric oxide synthase gene and is associated with coronary spasm. Circ. Supp. 96:I-315. (Abstr.)

38. Villamor, E., et al. 1997. Chronic intrauterine pulmonary hypertension impairs endothelial nitric oxide synthase in the ovine fetus. Am. J. Physiol. 272:L1013-L1020.

39. Faraci, F.M., Sigmund, C.D., Shesely, E.G., Maeda, N., and Heistad, D.D. 1998. Responses of carotid artery in mice deficient in expression of the gene for endothelial NO synthase. Am. J. Physiol. 274:H564-H570. 